\title{
Henriksen and Flora (1999) Revisited_A Literature Review on Third-Person Effects and
}

\section{Children/Adolescents*}

\author{
Gabriella Sandstig \\ University of Gothenburg, Gothenburg, Sweden
}

\begin{abstract}
In this literature review on TPE (third-person effects) and the behavioral consequences on children, the research questions posed are how the body of knowledge has evolved since the first empirical evidence of TPE among children and what knowledge gaps that remain. The traceable developments are two: (1) Compared to the vast amount of articles on TPE in general, the 59 identified on the topic of children are few and two thirds actually focus on adolescents/young adults rather than children. The reason put forward for studying younger children is the urge to prevent risky behavior through media literacy programs or pro-social advertisements; and (2) The studies have not primarily addressed results to support occurrence of TPE among children. Rather they support parental TPE or among the adolescents that TPE and reverse TPE occur due to certain kind of media content. The discussion on knowledge gaps that remain follow three themes: (1) Differentiations between self and others are in psychological studies implied to occur among children between the ages of 3-4 years old, yet no study address how children develop TPE; (2) There is a tendency to follow the more general development within TPE research with the renewed interest in behavioral consequences. But the primary behavioral consequence studied in TPE in general and within studies of TPE and children is support for censorship. Few studies address "real” behavioral consequences like parental mediation; and (3) There is also a need for more theoretically coherent research on the importance of social distance.
\end{abstract}

Keywords: third-person perception, TPE (third-person effects) hypothesis, TPE (third-person effects), children, social distance corollary

\section{Introduction}

TPE (third-person effects) also known as TPP (third-person perceptions) does not necessarily refer to real media effects. Rather it refers to a phenomenon of social differentiation between self and others meaning that people tend to ascribe stronger relative persuasive effects due to media messages on other people than

\footnotetext{
* Acknowledgements: As part of a larger project, The Globalization Initiative-Welfare and Health, funded by the Nordic Council of Ministers, this research was partly supported by the Nordic School of Public Health within a project on promoting healthy lifestyles among 3-5 year olds in the Nordic countries. Project manager for the latter project was Professor Karin Ringsberg. Both she and Professor Bengt Johansson at the department of journalism, media and communication have been helpful in giving valuable comments on the article.

Gabriella Sandstig, Ph.D., Department of Journalism, Media and Communication, University of Gothenburg.
} 
they ascribe themselves (Davison, 1983, p. 3; Perloff, 1999) ${ }^{1}$. Numerous articles have been written about TPE (see review by Perloff, 1999, 2002). A decade ago, Henriksen and Flora (1999) in a study on the perceived impact of pro- and anti-smoking ads, also provided evidence of that TPE occur among children (9-14 years old) and Chapin (1999) published an article on TPE and sexual risk taking among minority “at-risk” youth (8-17 years old) $)^{2}$.

This is a literature review on how the body of knowledge on TPE and children/adolescents has evolved since 1999. There is a special focus on behavioral consequences since most of the research on TPE is on the phenomena itself and the explanatory factors behind it. Originally, Davison (1983) referred to these consequences in terms of the TPE hypothesis, nowadays referred to as behavioral consequences of TPE. The hypothesis implies that the perception of how others may be influenced by the media can cause us to act. Our expectations of how others can come to be affected by media content lead to that we try to prevent this in our eyes negative influence (Salwen, 1998; Perloff, 2002). But even though parents may ascribe stronger media effects to other children than their own, they probably would try to regulate their own children from media exposure (Bybee, Robinson, \& Turow, 1982; van der Voort, Nikken, \& van Lil, 1992). For example, if parents think that their children are more affected by commercials on children's channels than themselves, they as a consequence of this perception might act upon it if they believe that the effect is negative to their children. They might try to prevent their children by changing to another channel or watch the programs together with them. The attitudes of the parents' have shown to be of important in the effects of media on children (Nathanson \& Yang, 2003, p. 111; Warren, 2005, p. 851; Funk, Brouwer, Curtiss, \& McBroom, 2009, pp. 981, 984). It is however unclear whether the attitudes of effects reflect parents' beliefs about children in general or their own in particular (Hoffner \& Buchanan, 2002, pp. 233-236). So both the perceptions of media effects amongst children and parents and the consequences of these perceptions are of essence. The research questions posed are: (1) How has the body of knowledge evolved since the first empirical evidence of TPE among children?; and (2) What knowledge gaps remain?.

\section{Method}

The search for articles was primarily conducted in Social Science Citation Index (Thomson Scientific/ISI (Institute for Scientific Information) Web Service) on search strings including the TPE and "children" or “adolescent” components. Corresponding meanings as TPE or TPP, “TPE hypothesis” or TPE and "behavioral consequences", "reversed TPE”, or "first-person perception” was also used. Complementary search was conducted in Academic Search Elite (EBSCO (Elton B Stephens Company)), CSA (Cambridge Scientific Abstracts) Social Science (including also IBSS: International Bibliography of the Social Sciences (CSA) and Sociological Abstracts (CSA)), IDB (International Data Base), International Encyclopedia of the Social \& Behavioral Sciences, Intute: Social Sciences, CIOS (Communication Institute for Online Scholarship)/ComAbstracts and Ncom: Nordicom Media Research Publications. Works which are irrelevant

\footnotetext{
${ }^{1}$ Consequently, there are other types of perceptions called first-person perception (Innis \& Zeitz, 1988), first-person effect (Tiedge, Silverblatt, Havice, \& Rosenfeldt, 1991) or reversed third-person effects (Cohen \& Davis, 1991) meaning that people tend to ascribe stronger effects on themselves than they do others. Second-person perception, second-person effect, shared effects or the influence of perceived influence (Gunther \& Storey, 2003) refers to that people ascribe persuasive effects on both others and themselves.

${ }^{2}$ Borzekowski, Flora, Feighery, and Schooler (1999) had been discarded due to similar results (and Flora is a co-author).
} 
have been discarded and those which are peripheral have been looked at critically. The complete list of the secondary sources that have passed through the review can be found in Table 1.

\section{Results}

\section{Few of the Articles Concerns Children Rather Adolescents or Young Adults}

Compared to the vast amount of articles on TPE in general, the 59 identified on the topic of children (from birth up to the age of puberty) are few and two thirds actually focus on adolescents/young adults rather than children (see Figure 1 and Table 1). In perspective the result follows the general attention paid to background factors within TPE research where none of similar background factors like age for instance gender and nationality (Perloff, 2002) or minorities (Mays \& Cochran, 1988) has gained much specific attention, rather the phenomena itself has.

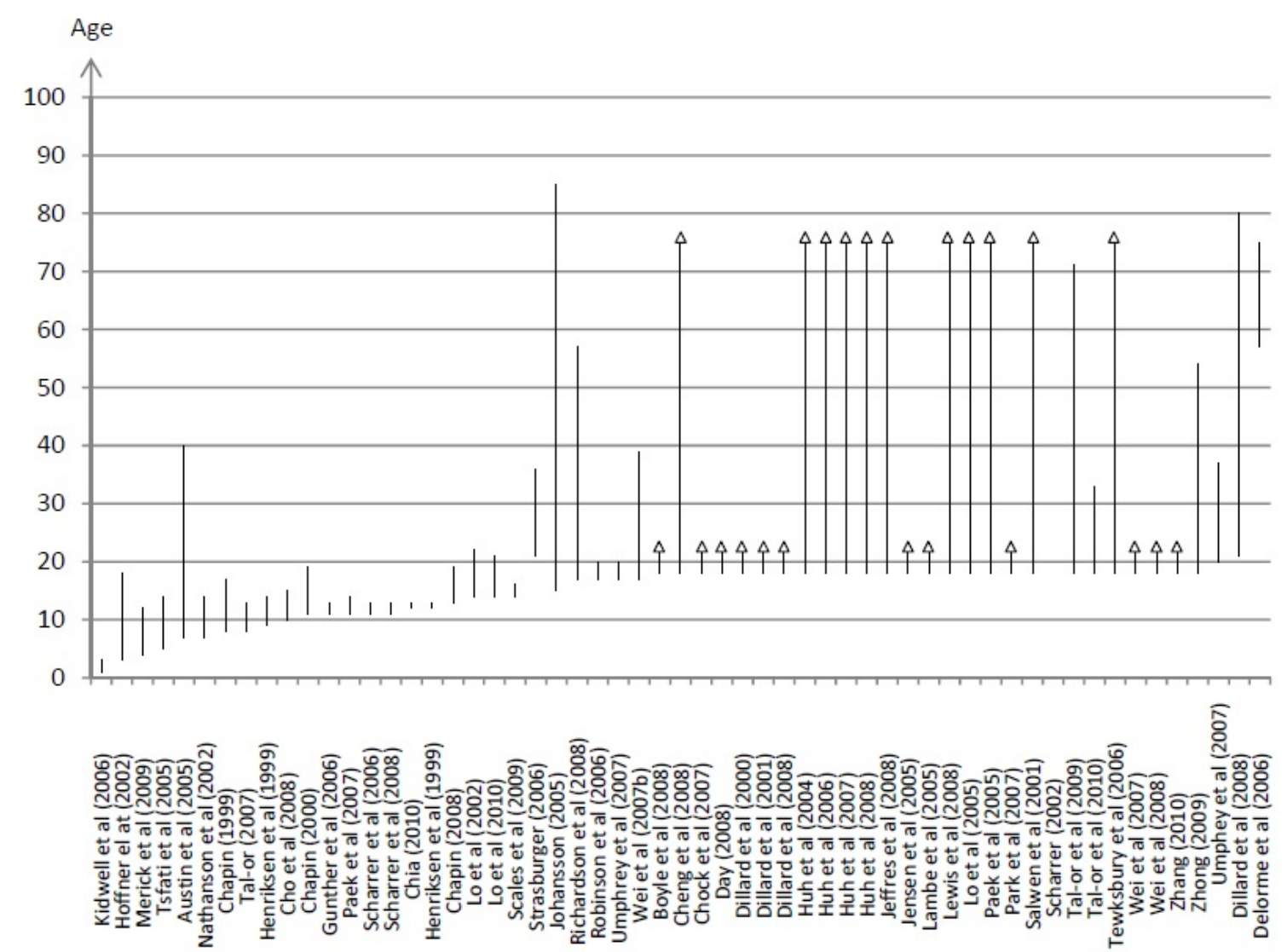

Figure 1. Age span of the children/adolescents in focus in the different studies (The age spans in the different studies range from the lowest to the highest age (some articles include more than one study). When ages are not specifically stated in the studies, they have in Figure 1 been estimated. College or university students maximum age is set to 22 years old and studies from the age of 18 and upward are set to the age of 75).

The majority of the (one third of the) studies that actually involve children (up to the ages of 14) encompass children in their early adolescents or preteens, the ages of 11-13 years old. The common denominator in these studies is that preteens have been chosen, because social identity is an important explanations for third-person perception (Duck, Hogg, \& Terry, 1999; Gunther \& Mundy, 1993; Gunther \& Thorson, 1992), and the preteen is the age when social identity and social behavior developments are especially observable (Scharrer \& Leone, 2006, p. 262). The focus on social identity and behavior is expressed by studies of how peer norms can exert especially 
forceful influence on adolescents. This through the adaptation to the perceived changes in the smoking behavior of others (Gunther, Bolt, Borzekowski, Liebhart, \& Dillard, 2006, p. 53), or the focus on if the age-based heuristics is used by the preteens in relations to those younger than themselves studying the perceptions of effects on aggression and desensitization of playing violent video games (Scharrer \& Leone, 2006, pp. 261-262). Not only risky behavior is studied, but also materialistic values and shopping norms and values among both pre-teens, their peers, and parents (Chia, 2010). In other words, in the interest of these studies is the pressure of the social norms of peers as part of the explanation for TPE.

Table 1

Articles Used in the Review With Age-Span, $N$-values, and Types of Uses

\begin{tabular}{|c|c|c|c|c|c|c|c|c|c|c|}
\hline Articles & Age 1 & N1 & Age 2 & N2 & $\mathrm{I}$ & II & III & IV & $\mathrm{V}$ & VI \\
\hline Austin et al. (2005) & $7-40$ & 119 & & & & $\mathrm{x}$ & & & $\mathrm{x}$ & \\
\hline Boyle et al. (2008) & A:18- & 141 & A:18- & 55 & & $\mathrm{x}$ & & $\mathrm{x}$ & $\mathrm{x}$ & \\
\hline Chapin (1999) & $8-17$ & 177 & & & $\mathrm{x}$ & $\mathrm{x}$ & & $\mathrm{x}$ & $\mathrm{x}$ & \\
\hline Chapin (2005) & $11-19$ & 1,105 & & & & $\mathrm{x}$ & & & & \\
\hline Chapin (2008) & $13-19$ & 350 & & & - & - & - & - & - & - \\
\hline Cheng et al. (2008) & $18-$ & 516 & & & & $\mathrm{x}$ & & & & \\
\hline Chia (2010) & $12-13$ & 697 & & & $\mathrm{x}$ & $\mathrm{x}$ & $\mathrm{x}$ & & & \\
\hline Cho et al. (2008) & $10-15$ & 246 & & & $\mathrm{x}$ & $\mathrm{x}$ & & & $\mathrm{x}$ & \\
\hline Chock et al. (2007) & A:18- & 89 & & & $\mathrm{x}$ & $\mathrm{x}$ & $\mathrm{x}$ & & & \\
\hline Day (2008) & A:18- & 135 & & & $\mathrm{x}$ & & & $\mathrm{x}$ & & \\
\hline Delorme et al. (2006) & $57-$ & 268 & & & & $\mathrm{x}$ & & & & \\
\hline Dillard et al. (2000) & A:18- & 140 & & & & $\mathrm{x}$ & & & & \\
\hline Dillard et al. (2001) & A:18- & 144 & & & & $\mathrm{x}$ & & & & \\
\hline Dillard et al. (2008) & A:18- & 155 & $21-80$ & 100 & & $\mathrm{x}$ & & & & \\
\hline Golan et al. (2008) & - & - & & & & $\mathrm{x}$ & & & & \\
\hline Gunther et al. (2006) & $11-13$ & 818 & & & & $\mathrm{x}$ & & & & \\
\hline Henriksen et al. (1999) & $12-13$ & 571 & $9-14$ & 676 & $\mathrm{x}$ & $\mathrm{x}$ & $\mathrm{x}$ & $\mathrm{x}$ & $\mathrm{x}$ & \\
\hline Hoffner et al. (2002) & $P: 3-18$ & 70 & & & $\mathrm{x}$ & & & $\mathrm{x}$ & & \\
\hline Huck et al. (2009) & - & - & & & & $\mathrm{x}$ & & & & $\mathrm{x}$ \\
\hline Huh et al. (2004) & $18-$ & 600 & & & & & & & $\mathrm{x}$ & $\mathrm{x}$ \\
\hline Huh et al. (2006) & $18-$ & 472 & & & & $\mathrm{x}$ & & & $\mathrm{x}$ & \\
\hline Huh et al. (2007) & $18-$ & 600 & $18-$ & 1,191 & & $\mathrm{x}$ & & & & \\
\hline Huh et al. (2008) & $18-$ & 600 & & & & $\mathrm{x}$ & & & $\mathrm{x}$ & \\
\hline Jeffres et al. (2008) & $18-$ & 505 & - & 2,172 & - & - & - & - & - & - \\
\hline Jensen et al. (2005) & A:18- & 243 & & & & $\mathrm{x}$ & & & & \\
\hline Johansson (2005) & $15-85$ & 3,000 & & & & $\mathrm{x}$ & & & & \\
\hline Kidwell et.al (2006) & $1-2,5$ & $473 \mathrm{~h}$ & & & $\mathrm{x}$ & & & & & \\
\hline Lambe et al. (2005) & $\mathrm{P}: 18-$ & 274 & & & $\mathrm{x}$ & $\mathrm{x}$ & & & & \\
\hline Lewis et al. (2008) & $18-$ & 201 & & & & $\mathrm{x}$ & & & & \\
\hline Lo et al. (2002) & C:14-22 & 2,713 & & & & $\mathrm{x}$ & & $\mathrm{x}$ & $\mathrm{x}$ & \\
\hline Lo et al. (2005) & $18-$ & 1,983 & & & & $\mathrm{x}$ & & & & \\
\hline Lo et al. (2010) & $14-21$ & 1,688 & & & & $\mathrm{x}$ & & & & \\
\hline Merick et al. (2009) & $P: 4-12$ & 171 & & & & $\mathrm{x}$ & & & & \\
\hline Nathanson et al. (2002) & $P: 7-14$ & 265 & & & $\mathrm{x}$ & & $\mathrm{x}$ & & & \\
\hline Paek et al. (2005) & $18-$ & 365 & & & & $\mathrm{x}$ & & & & \\
\hline Paek et al. (2007) & $11-14$ & 1,687 & & & & $\mathrm{x}$ & $\mathrm{x}$ & & & \\
\hline
\end{tabular}


(Table 1 continued)

\begin{tabular}{|c|c|c|c|c|c|c|c|c|c|c|}
\hline Articles & Age 1 & N1 & Age 2 & N2 & I & II & III & IV & $\mathrm{V}$ & VI \\
\hline Park et al. (2007) & $\mathrm{C}: 18-$ & 220 & & & & & $\mathrm{x}$ & & & \\
\hline Richardson et al. (2008) & $17-57$ & 156 & & & & $\mathrm{x}$ & & & & \\
\hline Robinson et al. (2006) & $17-20$ & 121 & $59-89$ & 94 & & $\mathrm{x}$ & & & & \\
\hline Roese et al. (2007) & - & & & & $\mathrm{x}$ & & & & & \\
\hline Salwen et al. (2001) & $18-$ & 236 & & & & & & & & $\mathrm{x}$ \\
\hline Scales et al. (2009) & $14-16$ & 78 & & & & & & $\mathrm{x}$ & & \\
\hline Scharrer (2002) & $18-$ & 624 & & & & $\mathrm{x}$ & & & & \\
\hline Scharrer et al. (2006) & $11-13$ & 118 & & & $\mathrm{x}$ & $\mathrm{x}$ & & & & \\
\hline Scharrer et al. (2008 & $11-13$ & 118 & & & $\mathrm{x}$ & $\mathrm{x}$ & $\mathrm{x}$ & & & $\mathrm{x}$ \\
\hline Stern (2005) & - & & & & - & - & - & - & - & - \\
\hline Strasburger (2006) & - & & & & - & - & - & - & - & - \\
\hline Tal-or (2007) & $8-13$ & 120 & $21-36$ & 60 & $\mathrm{x}$ & & & & & $\mathrm{x}$ \\
\hline Tal-or et al. (2009) & $18-71$ & 130 & & & & $\mathrm{x}$ & & & $\mathrm{x}$ & \\
\hline Tal-or et al. (2010) & $18-33$ & 100 & & & & & & $\mathrm{x}$ & & \\
\hline Tewksbury et al. (2006) & $18-$ & 309 & $18-$ & 407 & & $\mathrm{x}$ & & & $\mathrm{x}$ & \\
\hline Tsfati et al. (2005) & $5-14$ & 132 & & & $\mathrm{x}$ & $\mathrm{x}$ & $\mathrm{x}$ & $\mathrm{x}$ & $\mathrm{x}$ & \\
\hline Umphrey et al. (2007) & $17-20$ & 168 & $20-37$ & 166 & $\mathrm{x}$ & & $\mathrm{x}$ & & & \\
\hline WEI et al. (2007) & C:18- & 1,107 & & & & & & $\mathrm{x}$ & & \\
\hline WEI et al. (2007b) & $17-39$ & 754 & & & & $\mathrm{x}$ & $\mathrm{x}$ & $\mathrm{x}$ & & \\
\hline WEI et al. (2008) & $18-22$ & 107 & & & & $\mathrm{x}$ & & & & \\
\hline XU et al. (2008) & - & & & & $\mathrm{x}$ & & & & & \\
\hline ZHANG (2010) & A:18- & 112 & C:18- & 208 & & $\mathrm{x}$ & & & & \\
\hline ZHONG (2009) & $18-54$ & 465 & & & & & $\mathrm{x}$ & $\mathrm{x}$ & & \\
\hline
\end{tabular}

Notes. In some articles, more than one study is presented. The letters before age imply the following: A = university students; $\mathrm{C}=$ college students; and P = parents or caregivers to the ages specified. In the types of uses: $\mathrm{I}=$ TPE occur among adolescents/children; $\mathrm{II}=\mathrm{TPE} /$ reversed TPE due to certain kind of content; III = TPE increase with increased social distance; IV = TPE and motivational or individual factors; V = TPE and behavioral factors; and VI = TPE in a more general manner. In the Nordicom database Ncom, there are some overlaps of articles due to the fact that some of the reports are originally written in Swedish (Berglie, 2004 is compatible with the content of Johansson, 2005). The chapter by Gunther et al., (2000) will be included later (not included in this version due to lack of time to implement).

In the studies that include children from toddlers up to the age of 10, the author's interpretation of why these ages are included is twofold. The first case is that if we are to prevent risky behavior, we must know more about how to reach the younglings at an early. The first way is through the study of the impacts of education by an evaluation of a media literacy training program to prevent adolescents from substance abuse (Austin, Pinkleton, Hust, \& Cohen, 2005, pp. 75-76). The problem posed is that the lack of scientific studies of the effectiveness of the strategy leaves advocates open to skepticism with the goal to evaluate if programs designed to foster young peoples' skepticism towards advertises can make viewers less affected by advertisements (ibid). Another way is through learning more about how to design campaigns, how anti-drug ads can be improved to motivate 10-15 years old (Cho \& Boster, 2008, p. 170) or through studies if the understanding of the persuasive element of advertising comes with age, by comparing younger (8-13 years old) and older respondents (21-36 years old) (Tal-or, 2007, p. 405). The second case is a theoretical interest in the social distance between the parents and their children. This is elaborated in the section below.

\section{General Support of Occurrence of TPE Among Children Is Not the Primary Result}

The studies have not primarily addressed results to support the occurrence of TPE among children. In 
approximately $40 \%$ of the articles, the occurrence is discussed in a more general manner to show that children or adolescents follow the patterns of adults concerning TPE, meaning that they ascribe larger effects on others than on themselves. Two of these studies look closer at TPE and the age heuristic in itself, the tendency that the gap between how others and oneself are effected increase with increased age among the adolescents (Day, 2008, p. 246, Cho \& Boster, 2008, p. 171).

In the studies where there is a theoretical interest in the social distance between the parents and the children, the parents rather than the children/adolescents are the respondents. These studies do not address TPE among children/adolescents but studies PTPP (parental third person perception) and the results in these studies emphasize the similarity in TPE between child and parent. The object of study is either harmful television in general (Nathanson, Eveland, Park, \& Paul, 2002), televised violence or sex in particular (Hoffner \& Buchanan, 2002; Meirick, Sims, Gilchrist, \& Croucher, 2009), but also daytime drama (Tsfati, Ribak, \& Cohen, 2005). In comparing their own children to the children of others, other children are ascribed stronger media effects and their own child less as the well as the parent itself. An interpretation of this is that children are seen as extensions of the parents (Nathanson et al., 2002, p. 389). The youngest children in these studies of the parent's perceptions are three (Hoffner \& Buchanan, 2002), four (Meirick et al., 2009), five (Tsfati et al., 2005, p. 3), and seven (Nathanson et al., 2002) years old.

The most common characteristic in the results is not as expected the more general support of occurrence of TPE, rather the support TPE or reversed TPE due to specific media content or messages is. This result is found in nearly three fourth of the articles ${ }^{3}$. On one hand, these results support the fact that TPE increase with negative, unwanted, or controversial media content/message.

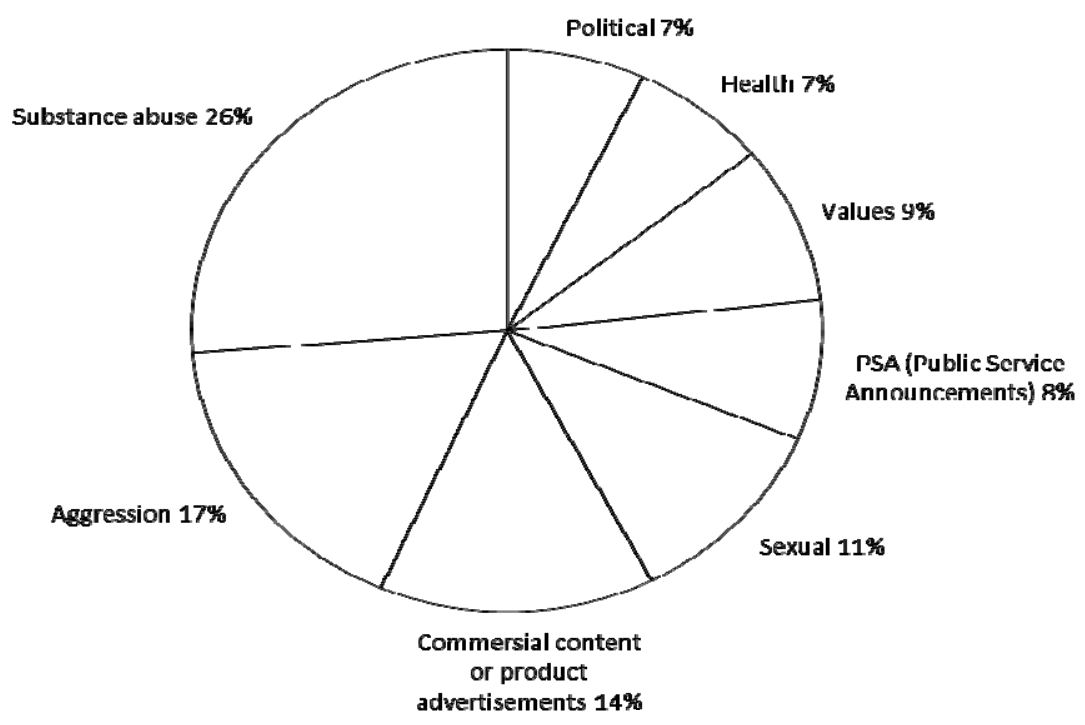

Figure 2. Types of content in articles on TPE and children/adolescents (The diagram above show the percentage of occurrence of different types of content studied in the articles on TPE and children/adolescents, $n=53$ ).

And on the other hand, they support that the reversed TPE increases with pro-social messages or when it is regarded positive to be influenced. In other words, as stated within TPE research, both the magnitude and

\footnotetext{
${ }^{3}$ One specific study can cover more than one characteristic.
} 
direction of TPE depend on the desirability of the message (Perloff, 2002). Risk related content like substance abuse, violence, pornography, or the prevention of risky behavior is the most common, especially the abuse of drugs, tobacco, and alcohol (see Figure 2). On the topic of drug related content and that TPE occur when a message is perceived negative or socially undesirable, there are studies that give support for behavioral consequences in banning DTC (direct-to-consumer) ads on prescription drugs (Huh, Delorme, \& Reid, 2004, p. 569; 2007, p. 379).

Drug related content is also used to support that pro-social messages like anti-drug use and attitudes towards drug use among adolescents lead to reversed TPE (Cho \& Boster, 2008, p. 171). "The results suggested that adolescents estimated the anti-drug ad effect on the basis of their behavioral experience, the self-anchored expectancy and of pro-social media effects” (ibid, p. 169). But not only respondent's perceptions and intended actions are studied. There are studies look closer at drug abuse and other related substance abuse like alcohol in movies and films from a health perceptive (Stern, 2005) and what primary care practitioners need to know about the influence of the media on adolescents Strasburger (2006). Risky content as tobacco is primarily studied in relation to anti-smoking messages. As discussed earlier with the intent to evaluate media literacy training in preventing risky behavior (Austin et al., 2005, p. 76). But also through an interest in the importance of peer norms "[...] suggesting that smoking related media content may have a significant indirect influence on adolescent smoking via its effects on perceived peer norms” (Gunther et al., 2006, p. 52). Even though the indirect effects of anti-smoking ads through peers were stronger than for pro-smoking ads, the results are that the both types influence susceptibility indirectly through peers (ibid), or in relation to specific media contexts like anti-smoking messages on television, radio, the Internet, in magazines and billboards or outdoor signs (Paek \& Gunther, 2007). On the topic of alcohol, TPE of beer commercials that encourage alcohol consumption (Lambe \& McLeod, 2005, pp. 281-282) or affects like humorous and fear-evoking anti-drink driving messages (Lewis, Watson, \& White, 2008) are studied. A conclusion from the latter being that content context (media type) is most relevant for TPE and behavioral consequences in relation to whom this significant “other” is (Lambe \& McLeod, 2005, p. 290).

Another type of content that relates to the prevention of the risky behavior ascribed above is studies of PSA (public service announcements). They are a type of non-profit specific type of ads, trying to prevent risky behavior like substance abuse but also other types of risky behavior, like preventing sexual risks with safe-sex ads (Chapin, 1999). Studied are emotional responses to PSA's and their perceived effectiveness of persuasion (Dillard \& Peck, 2000, 2001; Dillard \& Ye, 2008) with the result that the judgments on the perceived effectiveness even if two dimensional can be reduced to one. Most individuals reported using more than one referent (person or group) when they made the judgments but the referent changes with both type of message and judge. But also how arousing fast-paced radio PSA's, can decrease TPE (Chock, Fox, Angelini, Lee, \& Lang, 2007) with the explanation that is the largely the dominance of visual media that have been studied, not audio.

Generally studies of real effect studies of violence on aggression especially on children, is within media and communication (together with the studies of political campaigns) among the oldest in the field, and mostly researched within the context of television (see overviews by McQuail, 2009). In relation to TPE and children, the content related to aggression like violence or the prevention of violence is related to three different media type 
context: First, like real effects, TPE are studied in relation to televised violence where both the children/adolescents (Scharrer, 2002; Nathanson et al., 2002; Meirick et al., 2009) as well as the parents responses (Hoffner \& Buchanan, 2002) are in focus, and on the other hand in relation to both TPE and reversed TPE on anti-violence programs amongst the MTV generation (Chapin, 2005). Second, TPE are in relation to violent video games (Boyle, McLeod, \& Rojas, 2008; Scharrer \& Leone, 2006, 2008). Third, TPE are in relation to violence prevention in schools (Chapin, 2008).

Sexual content in relation to TPE has besides studies in relation to safe-sex behavior in relation to PSA messages studied from the point of comparing the support for censorship between violent and sexual media content (Meirick et al., 2009, p. 221; Nathanson et al., 2002). With the result that parental mediation and support for censorship occurred more frequently on account of sexual than violent television. Their use of protective behavior depended on perceived threat for their own and other children, and perceptions of self and response efficiency (ibid). But also as pornography on the Internet (Lo \& Wei, 2002, 2005), adult entertainment clubs (Lo, Wei, \& Wu, 2010) and pornographic videos that depict women as sex objects (Lambe \& McLeod, 2005). Other types of risky content are connected with health and environment issues like TPE on the out brake of bird-flu in Taiwan (Wei, Lo, \& Lu, 2007, 2008) or on news coverage of dioxin regulation and wolf reduction (Jensen et al., 2005).

But there are some exceptions to study of TPE in relation to risky content or risky behavior like political advertisements (Cheng et al., 2008; Richardson et al., 2008; Johansson, 2005; Paek, Pan, Sun, Abisaid, \& Houden, 2005; Wei \& Lo, 2007) or commercial content like perceptions of materialism (Chia, 2010) or positive product advertisement (Tal-or, 2007). But also related to different values like stereotypes of elderly (Robinson \& Umphery, 2006; Umphrey \& Robinson, 2007) or minorities (ZHONG, 2010), and views on femininity and masculinity (ZHANG, 2010), and perceptions of thinness (Park et al., 2007).

To grasp the different characteristics of the results in the articles under study the author has besides the general support for TPE, the support for parental TPE and TPE/reversed TPE found the following two ways that TPE among children/adolescents are discussed in $20 \%$ of the articles respectively: (1) to support motivational or other individual factors to explain TPE; and (2) to support that TPE increases with increased social distance and in specific relation to TPE hypothesis or behavior.

Individual factors as support for the importance of self-enhancement (Hoffner \& Buchanan, 2002, p. 235; Wei \& Lo, 2007, p. 371), ego-enhancement (Boyle et al., 2008, p. 166), and biased-optimism (Wei et al., 2007, p. 668; ZHONG (2009, p. 292) could play a part in explaining the occurrence of TPE. Nathanson et al. (2002) dealt with the motivational factors behind parental protective behavior. Their results show that protective behavior is related to four factors: content, perceptions of audience (TPE), perceptions of one's one abilities, and perceptions of responses effectiveness (ibid, pp. 400-402). As mentioned earlier also demographics like age is used as an individual factor to explain the occurrence of TPE (Day, 2008, p. 246) or gender (Scales, Monahan, Rhodes, Roskos-Ewoldsen, \& Johnson-Turbes, 2009, p. 752) was males displayed more apparent TPE than females. Most of the results presented in the articles that support that TPE increases with increased social distance and in specific relation to TPE hypothesis or behavior lead towards identified knowledge gaps. The characteristics of these studies are therefore discussed below in relation to the knowledge gaps that remain. 


\section{Discussion on What Knowledge Gaps That Remain}

The knowledge gaps that remain follow three themes: (1) Differentiations between self and others are in psychological studies implied to occur among children between the ages of 3-4 years old, yet no study address how children develop TPE; (2) There is a tendency to follow the more general development within TPE research with the renewed interest in behavioral consequences. But the primary behavioral consequence studied in TPE in general and within studies of TPE and children is support for censorship. Few studies address “real” behavioral consequences like parental mediation; and (3) There is also a need for more theoretically coherent research on the importance of social distance.

\section{A Lack of Studies on Occurrence and Development of TPE Among Children}

The question posed is at what age is it fruitful to begin research on TPE, and at what age does TPE begin? There are studies that show that even really young children between the ages of one and two and a half year old can sense how their parents and caretakers may view their conducts and how their views might matter to their action (Kidwell \& Zimmerman, 2006, p. 1). Stipek and Hoffman (1980) showed that children between three and six allocate higher rewards to themselves than others. With a reference to Henriksen and Flora (1999), there is also an article that claims that TPE occurs at such an early age as four (Roese \& Olson, 2007, pp. 133-134). But a mix-up must have been made between years and grade, because the youngest one in the article by Henriksen and Flora (1999) is in the fourth grade (meaning nine years old). So the actual ages when TPE first occur are unclear. But in the interest of further studies, it is stated that even though the differentiation between self and others does occurs at early ages, it is first at the age of seven that the differentiation occur as a regular pattern (Frey \& Ruble, 1990).

\section{There Is a Tendency to Follow the Development in the Field of TPE in General}

Dillard and Peck (2000, 2001) called for more research on the link between TPE and consequences on behavior. In another article, a meta-analysis on TPE and behavioral consequence, the authors urge us to move further, to leave the TPE perception hypothesis and move over to the behavioral hypothesis (Xu \& Gonzenbach, 2008, p. 376). The argument for this shift is taken from three of the most influential authors on TPE, Perloff (1999), and Gunther and Storey (2003). The reason for this within the common body of research (Salwen, 1998; Perloff, 1999; Gunther \& Storey, 2003) is that now that most about TPE is already known, it is time to deal with the really interesting parts of the original TPE hypothesis posed by Davison (1983, p. 3). But to bear in mind though, the expectations on the outcomes compared to studies of the perceptual part should be modest. The results of the meta-analysis show that when the authors compared behavioral consequences to TPE perceptual hypothesis the size of the effects on behavior was weaker and inconsistent (Xu \& Gonzenbach, 2008, p. 382).

But support for censorship has been the most studied behavioral consequence of TPE, both within the general studies of the TPE hypothesis as well as more specifically on children/adolescents. With the support of Rucinski and Salmon (1990) and Gunther (1995), Xu and Gonzenbach (2008, p. 367) argued that the most commonly researched TPE behavioral aspects are consequences in the form of support for censorship. In resemblance with what has been showed in this review, the most prominent body of research on consequences has also been within questions of support for censorship. What we learned from this research on children/adolescents is that it is not yet clear whether it is first, second- or third-person perceptions that lead to the 
most support for censorship. If the focus is to put on explaining the behavioral consequences, then preferably all the three perceptions should be caught up in further studies. But another reason or the call for more research on behavioral consequences within the research on children/adolescents is plausible. As showed in this review it is not that unusual (approximately 20\% of the articles cover these issues) with studies of behavioral consequences. The reason behind a renewed turn towards behavioral consequences is rather a more specific one: to leave consequences like support for censorship, and to begin to study "real" consequences. Like for example made in the study by Tewksbury, Moy, and Weis (2006), were emotional anxiety as a consequence of third person effects are studied. Like Tewksbury et al. (2006), Xu and Gonzenbach (2008, p. 375) at the beginning of their meta-analysis urged us to also move from studies of censorship to other areas of behavioral consequences. The authors' argument for that when it comes to other areas than censorship the links are mote contradictory (voting, self-image of towns, body image, etc.) (ibid, p. 377). Like in the problem of all effect studies made upon cross-sectional data like the data used in the study by Xu and Gonzenbach (2008, p. 375), there is however still a theoretical and methodological problem when it comes to causality (and other issues). Even though Tewksbury et al. (2006) were successful in analyzing consequences of third-person perception of violence on increased anxiety, the general results by Xu and Gonzenbach (2008) are discouraging. The latter study (meta-analysis) was not successful in to draw focus beyond censorship into real-life consequences of TPE. The reasons discussed are either that censorship is a unique behavior and that TPE behavior consequences are only true in specific context or that the research somehow is inconsistent (Xu \& Gonzenbach, 2008, p. 382). To be on the safe side when analyzing data on TPE behavioral consequences, both the support for censorship as well as alternative behavioral consequences should be included, like for instance parents' interventions on children's media consumptions.

A field of interest where "real” behavioral consequences of TPP on children can be found is within the field of parental mediation. When it comes to the behavioral aspect, if not actually studying the children themselves, there is another field of interest that could be relevant. The field is called parental mediation (Nathanson et al., 2002; Hoffner \& Buchanan, 2002; Tsfati et al., 2005) or parental third-person perception (Meirick et al., 2009, pp. 230-231). The article by Tsfati et al. (2005) made it clear when it comes to parental mediation, even if not specifically related to TPE is represented in the literature way before 1999 when Henriksen and Flora as well as Chapin wrote their articles on children and TPE. This leads to a whole new body of research. Most of the research that came across searching for studies on children/adolescents seems to primarily relate to television and seems to be from the 1990s. So it could be fruitful to bring the two complexes together in real time, for instance on parental mediation of online gaming and use of the Internet. More specifically in relation to young children as purposed between the ages of three to five and six to eight years of age is to focus on the parents' views of these younger groups, as performed when focus was on parental mediation on television shows and choice of friends (Tsfati et al., 2005) on television violence and support for censorship (Hoffner \& Buchanan, 2002) and on commercials and materialism (Meirick et al, 2009).

\section{More Theoretically Coherent Research on the Importance of Social Distance}

In relation to the social distance corollary the hypothesis: The more distant the social corollary, the larger the perceptual gap between self and others in estimating media effects (Wei \& Lo, 2007; ZHONG, 2009), could be further investigated. Especially the relationship between perceived impacts on one hand oneself, one's own 
child/children and the friends of one's child/children, and on the other hand the child self, the child's friends, and other children. Closeness in social distances has been shown to be larger with friends than with parents (were children ascribe greater influence on their parents due to tobacco advertisements, than they ascribe their friends, even those friends that smoke. See Chock et al., 2007, p. 621). But also the opposite when it comes to younger children, when the parents ascribed similar TPE on themselves as their own children (Nathanson et al., 2002, p. 389; Tsfati et al., 2005, p. 3). And if also other children are added to the models impact is greater on other children than their own (Tsfati et al., 2005). There can also be interesting results from studying the TPE inside the age heuristic, where older children asses' greater impact on younger children than themselves (Scharrer \& Leone, 2006, p. 212). Besides the methodological issues, that some of the results are not statistically significant, critique has been directed towards the article by Henriksen and Flora (1999) when it comes to the importance of a coherent use of concepts in measuring social distance and its direct or indirect influence on TPE (Umphrey \& Robinson, 2007, p. 313). As a general recommendation also the possibility to compare the results to the outcome of other TPE studies should be made possible, like for instance through studying differences between oneself and others, and as noted the questions are not to be separated (Nathanson et al., 2002). As well as studies of social distance and TPP are of interest for further studies, the relation to the TPE hypothesis is “[...] Severity of media influence on both one's own and others' children may be an important factor in research on protective behaviors" (Nathanson et al., 2002, p. 389). Table 2 is a conceptual model for further quantitative studies on TPE and TPE behavioral consequences built on the discussion above.

Table 2

Conceptual Model on the Social Distance Corollary, and TPE and TPE Hypothesis on Children/Adolescents

\begin{tabular}{|l|l|l|l|}
\hline Degree of control & \multicolumn{3}{|c|}{ Social distance } \\
\hline One hand & Oneself & Your friends/acquaintances & Other people in general \\
\hline Other hand & Your own child/children & Children of friends/acquaintances & Others children in general \\
\hline Control & & & \\
\hline Censorship & & & \\
\hline
\end{tabular}

Finally, it is striking that there are few studies performed outside of America. TPE are said to differ with media types, media content, and cultures (Cohen \& Davis, 1991; Gunther, 1991; Gunther \& Thorson, 1992; Henriksen \& Flora, 1999; Hoffner et al., 2001; Mutz, 1989; Perloff, 1999; Rojas, Dhavan, \& Faber, 1996; Rucinski \& Salomon, 1990; Scharrer, 2002). But it is remarkable if we look at context as in country, only two studies relate to European countries, and only one study relates to a Nordic country (Johansson, 2005).

\section{Conclusions}

TPE also known as TPP refer to a phenomenon of social differentiation between self and others meaning that people tend to ascribe stronger relative persuasive effects due to media messages on other people than they ascribe themselves. In the end of the 1990s, provided evidence of that TPE also occur among children. In this literature review, the research questions posed are how the body of knowledge has evolved since the first empirical evidence of TPE among children and what knowledge gaps that remain. There is a special focus on behavioral consequences since most of the research on TPE is on the phenomena itself and the explanatory factors behind it. 
The results are that the traceable developments are two. The first tracable development is that compared to the vast amount of articles on TPE in general, the 59 identified articles on the topic of children are few and two thirds actually focus on adolescents/young adults rather than children. The reason put forward for studying younger children is the urge to prevent risky behavior through media literacy programs or pro-social advertisements. The second tracable development is that the studies have not primarily addressed results to support occurrence of TPE among children. Rather they support parental TPE or among the adolescents that TPE and reverse TPE occur due to certain kind of media content. The discussion on knowledge gaps that remain follows three themes: The first theme is that the differentiations between self and others in psychological studies are implied to occur among children between the ages of 3-4 years old, yet no study address how children develop TPE. The second theme is that there is a tendency to follow the more general development within TPE research with the renewed interest in behavioral consequences. But the primary behavioral consequence studied in TPE in general and within studies of TPE and children is still support for censorship. Few studies address "real" behavioral consequences like parental mediation. The third theme is that there is also a need for more theoretically coherent research on the importance of social distance.

\section{References}

Austin, E. W., Pinkleton, B. E., Hust, S. J. T., \& Cohen, M. (2005). Evaluation of an American legacy foundation Washington state department of health media literacy pilot study. Health Communication, 18(1), 75-95.

Borzekowski, D. G. L., Flora, J. A., Feighery, E., \& Schooler, C. (1999). The perceived influence of cigarette advertisements and smoking susceptibility among seventh graders. Journal of Health Communication, 4(2), 105-118.

Boyle, M. P., McLeod, D. M., \& Rojas, H. (2008). The role of ego enhancement and perceived message exposure in third-person judgments concerning violent video games. American Behavioral Scientist, 52(2), 165-185.

Bybee, C., Robinson, D., \& Turow, J. (1982). Determinants of parental guidance of children's television viewing for a special subgroup: Mass media scholars. Journal of Broadcasting, 26, 697-710.

Chapin, J. R. (1999). Third-person perception and sexual risk taking among minority "at-risk” youth. Mass Communication and Society, 2(3 \& 4), 163-173.

Chapin, J. R. (2005). I want my FPP: Reversing third-person perception for the MTV generation. The Social Science Journal, 42, 453-457.

Chapin, J. R. (2008). Youth perceptions of their school violence risks. Adolescents, 43(171), 461-471.

Cheng, H., \& Riffe, D. (2008). Attention, perception, and perceived effects: Negative political advertising in a battleground state of the 2004 presidential election. Mass Communication and Society, 11(2), 177-196.

Chia, S. C. (2010). How social influence mediates media effects on adolescents' materialism. Communication Research, 37(3), 400-419.

Cho, H. Y., \& Boster, F. J. (2008). First and third person perceptions on anti-drug ads among adolescents. Communication Research, 35(2), 169-189.

Chock, T. M., Fox, J. R., Angelini, J. R., Lee, S., \& Lang, A. (2007). Telling me quickly—How arousing fast-paced PSAs decrease self-other differences. Communication Research, 34(6), 618-636.

Cohen, J., \& Davis, R. G. (1991). Third-person effects and the differential impact in negative political advertising. Journalism \& Mass Communication Quarterly, 68, 680-688.

Davison, P. (1983). The third-person effect in communication. The Public Opinion Quarterly, 47(1), 1-15.

Day, A. G. (2008). Out of the living room and into the voting booth-An analysis of corporate public affairs advertising under the third-person effect. American Behavioral Scientist, 52(2), 243-260.

DeLorme, D. E., Huh, J., \& Reid, L. N. (2006). Perceived effects of direct-to-consumer (DTC) prescription drug advertising on self and others-A third-person effect study of older consumers. Journal of Advertising, 35(3), 47-65.

Dillard, J. P., \& Peck, E. (2000). Affect and persuasion-Emotional responses to public service announcements. Communication Research, 27(4), 461-495. 
Dillard, J. P., \& Peck, E. (2001). Persuasion and the structure of affect—Dual systems and discrete emotions as complementary models. Human Communication Research, 27(1), 38-68.

Dillard, J. P., \& Ye, S. (2008). The perceived effectiveness of persuasive messages: Questions of structure, referent, and bias. Journal of Health Communication, 13(2), 149-168.

Duck, J. M., Hogg, M. A., \& Terry, D. J. (1999). Social identity and perceptions of media persuasion: Are we always less influenced than others?. Journal of Applied Social Psychology, 29, 1879-1899.

Frey, K. S., \& Ruble, D. N. (1990). Strategies for Comparative evaluation: Maintaining a sense of competence across the life-span. In R. J. Stenberg \& J. Kollegian (Eds.), Competence considered. New Haven, C.T.: Yale University Press.

Funk, J. B., Brouwer, J., Curtiss, K., \& McBroom, E. (2009). Parents' of preschoolers: Expert media recommendations and ratings knowledge, media-effects beliefs, and monitoring practices. Pediatrics, 123(3), 981-988.

Golan, G. J., \& Day, A. G. (2008). The first-person effect and its behavioral consequences: A new trend in the twenty-five year history of third-person effect research. Mass Communication and Society, 11(4), 539-556.

Gunther, A. C. (1991). What we think others think. Communication Research, 18(3), 355-372.

Gunther, A. C. (1995). Overrating the X-rating: The third-person perception and support for censorship of pornography. Journal of Communication, 45(1), 27-38.

Gunther, A. C., \& Mundy, P. (1993). Biased optimism and the third-person effect. Journalism Quarterly, 70, 58-67.

Gunther, A. C., \& Storey, J. D. (2003). The influence of presumed influence. Journal of Communication, 53(2), 199-215.

Gunther, A. C., \& Thorson, E. (1992). Perceived persuasive effects of product commercials and public-service announcements: 3rd-person effects in new domains. Communication Research, 19(5), 574-596.

Gunther, A. C., Bolt, D., Borzekowski, D. L. G., Liebhart, J. L., \& Dillard, J. P. (2006). Presumed influence on peer norms: How mass media indirectly affect adolescent smoking. Journal of Communication, 56(1), 52-68.

Henriksen, L., \& Flora, J. A. (1999). Third-person perception and children: Perceived impact of pro- and anti-smoking ads. Communication Research, 26(6), 643-665.

Hoffner, C., \& Buchanan, M. (2002). Parents' responses to television violence: The third-person perception, parental mediation, and support for censorship. Media Psychology, 4(3), 231-252.

Hoffner, C., Plotkin, R. S., Buchanan, M., Anderson, J. D., Kamigaki, S. K., Hubbs, L. A., ... \& Pastorek, A. (2001). The third-person effect in perceptions of the influence of television violence. Journal of Communication, 51(2), 283-299.

Huck, I., Quiring, O., \& Brosius, H. B. (2009). Perceptual phenomena in the agenda setting process. International Journal of Public Opinion Research, 21(2), 139-164.

Huh, J., \& Langteau, R. (2007). Presumed influence of direct-to-consumer (DTC) prescription drug advertising on patients-The physician's perspective. Journal of Advertising, 36(3), 151-172.

Huh, J., DeLorme, D. E., \& Reid, L. (2006). Perceived third-person effects and consumer attitudes on preventing and banning DTC advertising. The Journal of Consumer Affairs, 40(1), 90-116.

Huh, J., DeLorme, D. E., \& Reid, L. (2008). Operationalizing the second-person effects and its relationship to behavioural outcomes to direct-to-consumer advertising. American Behavioral Scientist, 52(2), 186-207.

Huh, J., Delorme, D. E., \& Reid, L. N. (2004). The third-person effect and its influence on behavioral outcomes in a product advertising context: The case of direct-to-consumer prescription drug advertising. Communication Research, 31(5), 568-599.

Innis, J. M., \& Zeitz, H. (1988). The public's view of the impact of the mass media: A test of the "third person" effect. European Journal of Social Psychology, 18, 457-463.

Jeffres, L. W., Neuendorf, K., Brackena, C. C., \& Atkin, D. (2008). Integrating theoretical traditions in media effects: Using third-person effects to link agenda-setting and cultivation. Mass Communication and Society, 11, 470-491.

Jensen, J. D., \& Hurley, R. J. (2005). Third-person effects and the environment: Social distance, social desirability, and presumed behavior. Journal of Communication, 55(2), 242-256.

Johansson, B. (2005). The third-person effect. Only a media perception?. Nordicom Review, 26(1), 81-94.

Kidwell, M., \& Zimmerman, D. (2006). "Observability” in the interactions of very young children. Communication Monographs, 73(1), $1-28$.

Lambe, J. L., \& McLeod, D. M. (2005). Understanding third-person perception processes: Predicting perceived impact on self and others for multiple expressive contexts. Journal of Communication, 55(2), 277-291.

Lewis, I., Watson, B., \& White, K. M. (2008). An examination of message-relevant affect in road safety messages: Should road safety advertisements aim to make us feel good or bad?. Transportation Research Part F-traffic Psychology and Behaviour, 11(6), 403-417. 
Lo, V. H., \& Wei, R. (2002). Third-person effect, gender, and pornography on the Internet. Journal of Broadcasting \& Electronic Media, 46(1), 13-33.

Lo, V. H., \& Wei, R. (2005). Perceptual differences in assessing the harm of patronizing adult entertainment clubs. International Journal of Public Opinion Research, 18(4), 475-487.

Lo, V. H., Wei, R., \& Wu, H. M. (2010). Examining the first, second and third-person effects of Internet pornography on Taiwanese adolescents: Implications for the restriction of pornography. Asian Journal of Communication, 20(1), 90-103.

Mays, V. M., \& Cochran, S. D. (1988). Issues in the perception of AIDS risk and risk reduction activities by Black and Hispanic/Latina Women. American Psychologyst, 43, 949-957.

McQuail, D. (2009). McQuail's mass communication theory (5th ed.). London: Sage Publication.

Meirick, P. C., Sims, J. D., Gilchrist, E. S., \& Croucher, S. M. (2009). All the children are above average: Parents' perceptions of education and materialism as media effects on their own and other children. Mass Communication and Society, 12(2), $217-237$.

Mutz, D. (1989). The influence of perceptions of media influence. International Journal of Public Opinion Research, 1(1), 3-24.

Mutz, D. (1994). Contextualizing personal experience: The role of mass media. American Journal of Political Science, 56, 689-714.

Nathanson, A. I., \& Yang, M. S. (2003). The effects of mediation content and form on children's responses to violent television. Human Communication Research, 29(1), 111-134.

Nathanson, A. I., Eveland, W. P., Park, H. S., \& Paul, B. (2002). Perceived media influence and efficacy as predictors of caregivers' protective behaviors. Journal of Broadcasting \& Electronic Media, 46(3), 385-410.

Paek, H. J., \& Gunther, A. C. (2007). How peer proximity moderates indirect media influence on adolescent smoking. Communication Research, 34(4), 407-432.

Paek, H. J., Pan, Z. D., Sun, Y., Abisaid, J., \& Houden, D. (2005). The third-person perception as social judgment-An exploration of social distance and uncertainty in perceived effects of political attack ads. Communication Research, 32(2), 143-170.

Park, S. Y., Yun, G. W., McSweeney, J. H., \& Gunther, A. C. (2007). Do third-person perceptions of media influence contribute to pluralistic ignorance on the norm of ideal female thinness?. Sex Roles, 57(7-8), 569-578.

Perloff, R. M. (1999). The third-person effect: A critical review and synthesis. Media Psychology, 1, 353-378.

Perloff, R. M. (2002). The third-person effect. In J. Bryant \& D. Zillmann (Eds.), Media effects: Advances in theory and research. Mahwah, N.J.: Lawrence Erlbaum Associates.

Richardson, J. D., Huddy, W. P., \& Morgan, S. M. (2008). The hostile media effect, biased assimilation, and perceptions of a presidential debate. Journal of Applied Social Psychology, 38(5), 1255-1270.

Robinson, T., \& Umphery, D. (2006). First- and third-person perceptions of images of older people in advertising: An inter-generational evaluation. International Journal of Aging \& Human Development, 62(2), 159-173.

Roese, N. J., \& Olson, J. M. (2007). Better, stronger, faster self-serving judgment, affect regulation, and the optimal vigilance hypothesis. Perspectives on Psychological Science, 2(2), 124-141.

Rojas, H., Dhavan, V. S., \& Faber, R. J. (1996). For the good of others: Censorship and the third-person effect. International Journal of Public Opinion Research, 8, 163-186.

Rucinski, D., \& Salmon, C. (1990). The “other” as the vulnerable voter: A study of the third-person effect in the 1988 U.S. presidential campaign. International Journal of Public Opinion Research, 2, 345-368.

Salwen, M. B. (1998). Perceptions of media influence and support for censorship: The third-person effect in the 1996 presidential campaign. Communication Research, 25, 259-285.

Salwen, M. B., \& Dupagne, M. (2001). Third-person perception of television violence: The role of self-perceived knowledge. Media Psychology, 3(3), 211-236.

Scales, M. B., Monahan, J. L., Rhodes, N., Roskos-Ewoldsen, D., \& Johnson-Turbes, A. (2009). Adolescents’ perceptions of smoking and stress reduction. Health Education \& Behavior, 36(4), 746-758.

Scharrer, E. (2002). Third-person perception and television violence: The role of out-group stereotyping in perceptions of susceptibility to effects. Communication Research, 29(6), 681-704.

Scharrer, E., \& Leone, R. (2006). I know you are but what am I? Young people's perceptions of varying types of video game influence. Mass Communication and Society, 9, 261-268.

Scharrer, E., \& Leone, R. (2008). First-person shooters and the third-person effect. Human Communication Research, 34(2), 210-327.

Stern, S. R. (2005). Messages from teens on the big screen: Smoking, drinking, and drug use in teen-centered films. Journal of Health Communication, 10(4), 331-346.

Stipek, D., \& Hoffman, J. (1980). Development of children’s performance-related judgments. Child Development, 51, 912-914. 
Strasburger, V. C. (2006). Risky business: What primary care practitioners need to know about the influence of the media on adolescents. Primary Care, 33(2), 317-348.

Tal-Or, N. (2007). Age and third-person perception in response to positive product advertisements. Mass Communication \& Society, 10(4), 403-422.

Tal-Or, N., \& Drukmana, D. (2010). Third-person perception as an impression management tactic. Media Psychology, 13, $301-322$.

Tal-Or, N., Shilo, S., \& Meister, T. (2009). Third-person perception and purchase behavior in response to various selling methods. Psychology \& Marketing, 26(12), 1091-1107.

Tewksbury, D., Moy, P., \& Weis, D. S. (2006). Preparations for Y2K: Revisiting the behavioral component of the third-person effects. Journal of Communication, 54(1), 138-155.

Tiedge, J. T., Silverblatt, A., Havice, M. J., \& Rosenfeldt, R. (1991). Discrepancy between perceived first-person and third-person mass media effects. Journalism Quarterly, 68, 141-154.

Tsfati, Y., Ribak, R., \& Cohen, J. (2005). Rebelde way in Israel: Parental perceptions of television influence and monitoring of children's social and media activities. Mass Communication \& Society, 8(1), 3-22.

Umphrey, D., \& Robinson, T. (2007). Negative stereotypes underlying other-person perceptions of the elderly. Educational Gerontology, 33(4), 309-326.

van der Voort, T. H. A., Nikken, P., \& van Lil, J. E. (1992). Replication: Determinants of parental guidance of children’s television viewing: A Dutch replication study. Journal of Broadcasting \& Electronic Media, 36(1), 61-74.

Warren, R. (2005). Parental mediation of children's television viewing in low-income families. Journal of Communication, 55(4), 847-863.

Wei, R., \& Lo, V. H. (2007). The third-person effects of political attack ads in the 2004 US presidential election. Media Psychology, 9(2), 367-388.

Wei, R., Lo, V. H., \& Lu, H. Y. (2007). Reconsidering the relationship between the third-person perception and optimistic bias. Communication Research, 34(6), 665-684.

Wei, R., Lo, V. H., \& Lu, H. Y. (2008). Third-person effects of health news—Exploring the relationships among media exposure, presumed media influence, and behavioral intentions. American Behavioral Scientist, 52(2), 261-277.

Xu, J., \& Gonzenbach, W. J. (2008). Does a perceptual discrepancy lead to action a meta-analysis of the behavioral component of the third-person effect. International Journal of Public Opinion Research, 20(3), 375-385.

ZHANG, J. G. (2010). Self-enhancement on a self-categorization leash: Evidence for a dual-process model of first- and third-person perceptions. Human Communication Research, 36(2), 190-217.

ZHONG, Z. J. (2009). Third-person perceptions and online games: A comparison of perceived antisocial and prosocial game effects. Journal of Computer-Mediated Communication, 14(2), 286-306. 